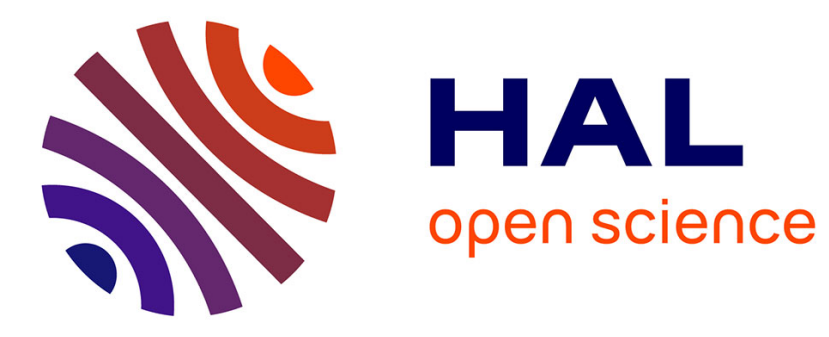

\title{
Cracking and durability of composites in a marine environment
}

Malick Diakhaté, Nicolas Tual, Nicolas Carrère, Peter Davies

\section{To cite this version:}

Malick Diakhaté, Nicolas Tual, Nicolas Carrère, Peter Davies. Cracking and durability of composites in a marine environment. Challenges in mechanics of time dependent materials: volume 2, Springer, pp.1-8, 2017, Conference Proceedings of the Society for Experimental Mechanics Series book series (CPSEMS), 978-3-319-41542-0. 10.1007/978-3-319-41543-7_1 . hal-01710252

\section{HAL Id: hal-01710252 \\ https://hal-ensta-bretagne.archives-ouvertes.fr/hal-01710252}

Submitted on 9 Jun 2021

HAL is a multi-disciplinary open access archive for the deposit and dissemination of scientific research documents, whether they are published or not. The documents may come from teaching and research institutions in France or abroad, or from public or private research centers.
L'archive ouverte pluridisciplinaire HAL, est destinée au dépôt et à la diffusion de documents scientifiques de niveau recherche, publiés ou non, émanant des établissements d'enseignement et de recherche français ou étrangers, des laboratoires publics ou privés.

\section{(c)(1)}

Distributed under a Creative Commons Attribution| 4.0 International License 


\title{
Cracking and Durability of Composites in a Marine Environment
}

\author{
Malick Diakhate, Nicolas Tual, Nicolas Carrere, and Peter Davies
}

\begin{abstract}
New renewable marine energy sources are increasingly being pursued as alternatives since they represent an important political and economic challenge for countries. Among these new energy sources, marine tidal turbines are growing considerably. Manufacturers used thick composite material to design most of the tidal turbine blades. To ensure the lifetime of the latter, it is necessary to develop damage models that take into account sea water, and analyse its effects on composite materials.

This paper presents results from laboratory tests that were conducted to investigate the cracking of composite materials before sea water ageing. Two testing methods, image processing and acoustic emission (AE) techniques were used to evaluate the crack density within the material. Samples of the Infused and Pre-preg materials with a $\left[0_{2}, 90_{2}\right]_{\mathrm{s}}$ stacking sequence were prepared and tested in tension on an electro-mechanical testing machine. Under these stresses, the material response results in a release of energy in the form of transient elastic waves that are recorded by AE sensors. By means of the $\mathrm{AE}$ technique, the monitoring of material damage lies in the ability to identify the most relevant descriptors of cracking mechanisms. The latter are identified by clustering the AE data. A K-means++ algorithm was used, and two AE featurespeak frequency and number of counts-represent adequately the AE events clustering. This unsupervised classification allows the AE events that were generated by intra-laminar cracks to be identified. Results show a good correlation between normalized crack density evaluated by image processing, and the one monitored by means of AE cluster analysis.
\end{abstract}

Keywords Acoustic emission $\bullet$ Crack monitoring $\bullet$ Cluster analysis $\bullet$ Image processing $\bullet$ Tidal turbine

\subsection{Introduction}

Over the last 50 years composite materials have found many applications in the marine domain, particularly in the yachting and offshore energy industries [1,2]. Composite materials are used in some offshore structures and new renewable energy applications are being developed such as tidal turbine blades. Tidal turbines offer an exciting opportunity to exploit ocean current flows to generate energy. The reliability of these structures, in a very severe environment, is crucial to the profitability of tidal current energy systems. These structures are subjected to many forces such as ocean tides, waves, storms but also to various marine aggressions, such as sea water and corrosion. A previous study [3] has highlighted the sensitivity of durability to the choice of composite components (fibre, resin, surface treatment of fibres). That work was carried out on thin composites reinforced by glass fibres. However, the majority of tidal turbine developers (MCT SeaGen, Alstom/TGL, Atlantis, Sabella, etc.) have preferred carbon fibre composite blades and the composite thicknesses are very large, especially in the area of connection between blade and hub.

Transverse cracking (intra-laminar) is the principal damage mechanism in unidirectional composite laminates loaded off-axis. A transverse crack is often followed by debonding at the plies interface. This micro-debonding can have a major

\author{
M. Diakhate $(\bowtie)$ \\ Université Bretagne Occidentale, FRE CNRS 3744, IRDL, 43 Quai de Léon, F-29600 Morlaix, France \\ e-mail: malick.diakhate@univ-brest.fr \\ N. Tual \\ LUNAM, Université de Nantes, Institute for Research in Civil and Mechanical Engineering GeM, \\ CNRS UMR 6183/FR 3743, 58 Rue Michel Ange, F-44600 Saint-Nazaire, France \\ N. Carrere \\ Ensta Bretagne, FRE CNRS 3744, IRDL, 2 Rue François Verny, F-29200 Brest, France \\ P. Davies \\ IFREMER, Centre Bretagne, Technopole Brest Iroise, F-29280 Plouzané, France
}


influence on both transverse cracking saturation [4] and on the composite out-of-plane strength. As a result, the lifetime of composites will be dominated by their inter-laminar or out-of-plane response.

The purpose of this paper is to characterize the mechanical behavior before sea water ageing of different carbon/epoxy composites for tidal turbine blade applications. Tensile loading was applied to composite samples with different stacking sequences of 0 and $90^{\circ}$ layers, and the intra-laminar crack evolution was monitored by means of two methods: image processing and acoustic emission. The mechanical behavior of the composite was evaluated in terms of crack density within the material. The monitoring of the crack kinetics, which corresponds to interfacial debonding and mesoscopic cracks in $90^{\circ}$ plies, was performed by means of the $\mathrm{AE}$ technique. Cluster analysis of $\mathrm{AE}$ events was applied to identify the acoustic signature of the intra-laminar cracks. This acoustic signature was validated by comparing the normalized crack density resulting from the $\mathrm{AE}$ technique with results from image processing.

\subsection{Laboratory Experimental Set-Up}

This section is devoted to a description of the laboratory tests that were conducted to investigate intra-laminar cracks within the material under tensile loading. The experimental conditions (composite samples, mechanical loading conditions, etc.) are described. Both the AE equipment specifications and the sample preparation are presented. Figure 1.1 provides a general overview of both the materials and the sample preparation procedure.

a

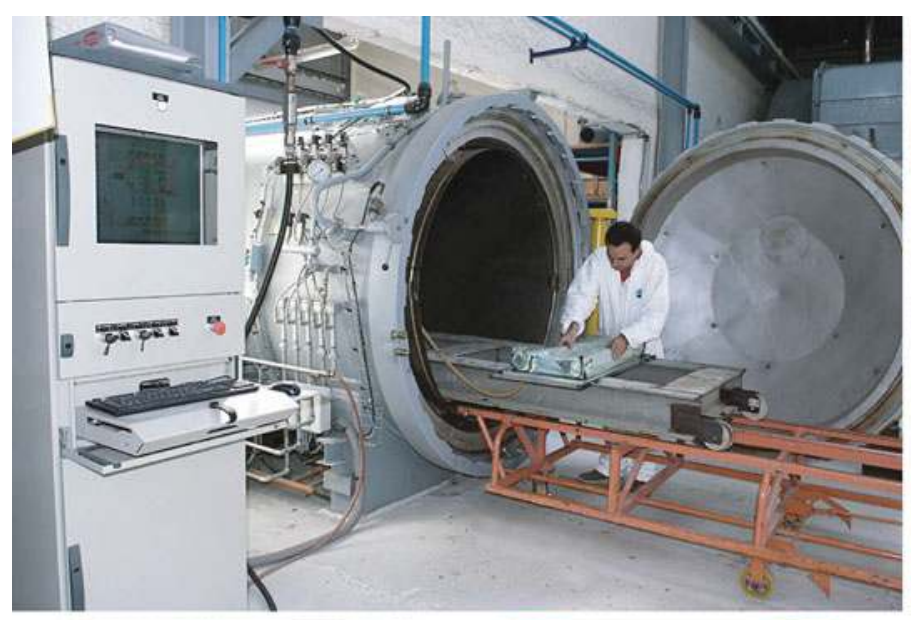

b

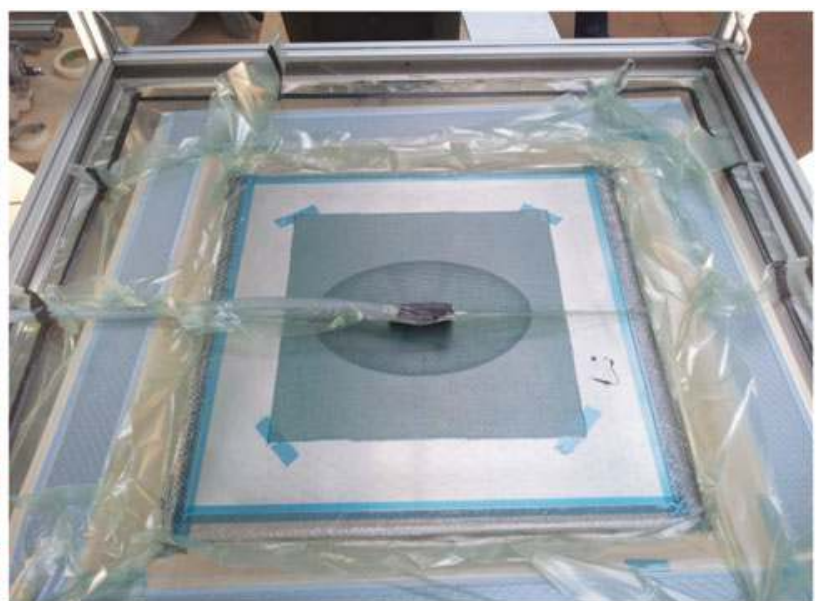

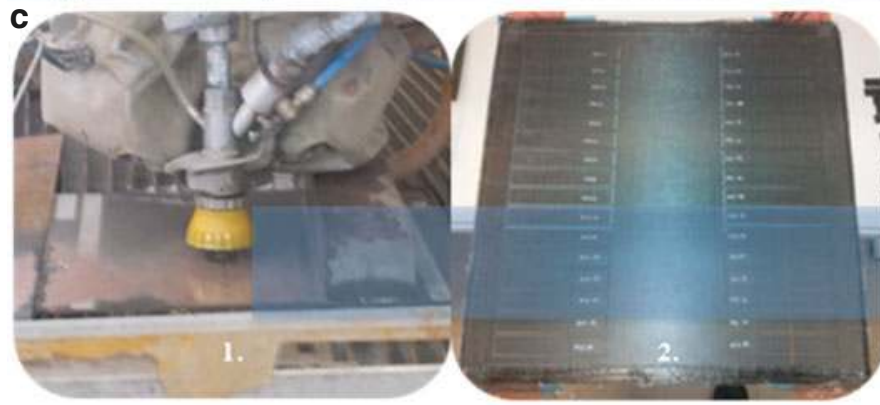
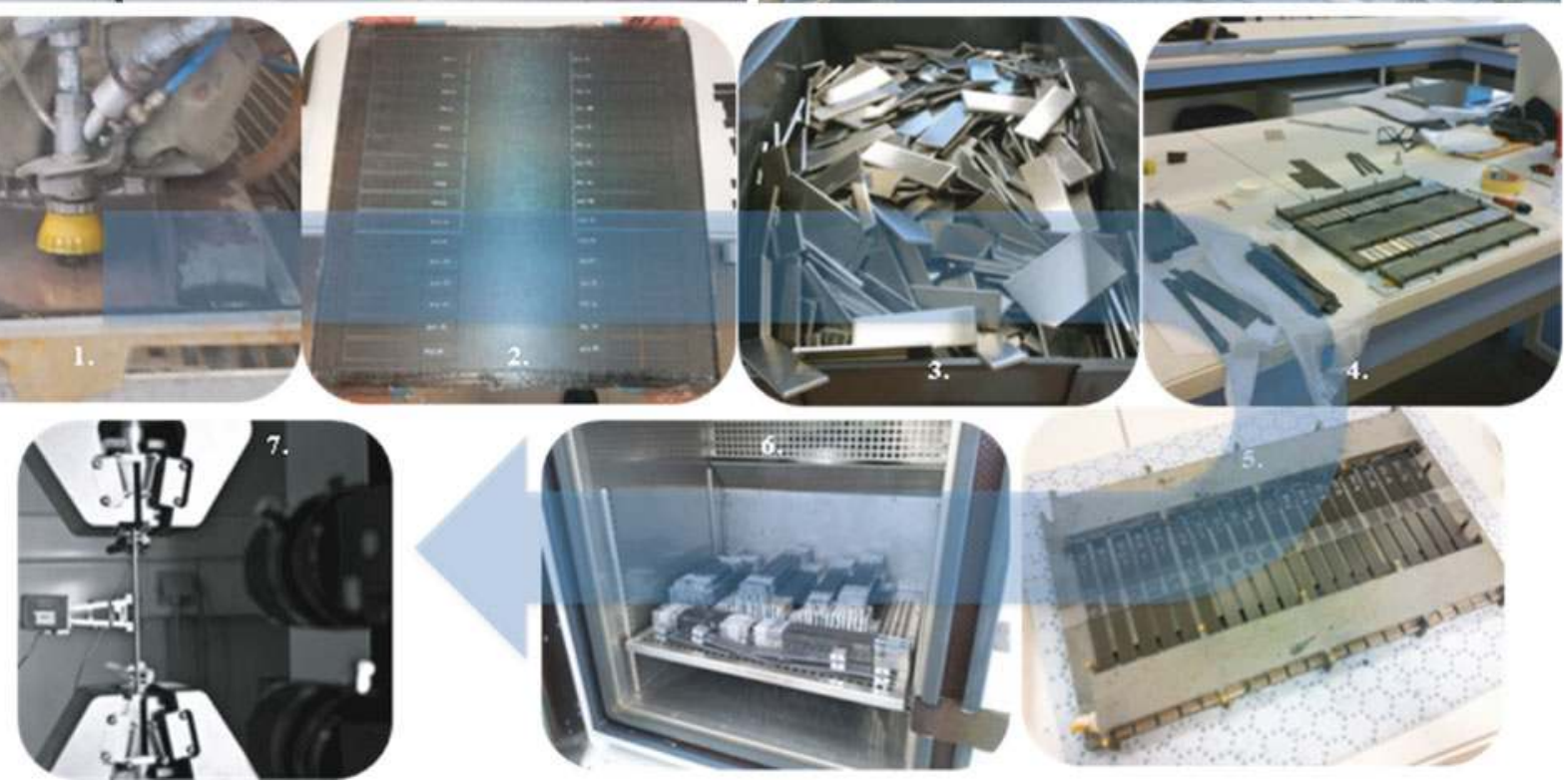

Fig. 1.1 Composite materials and specimen preparation procedure: (a) A pre-preg part under vacuum going into the FMC autoclave-(b) Infusion process (IRDL Laboratory) - (c) preparation procedure for all specimens 


\subsubsection{Composite Materials and Specimens}

In this study three processes and materials have been chosen to produce samples for tests, for characterization before and after sea water ageing. The analysis presented in this paper however has been restricted to an interpretation of results for just two materials before sea water ageing.

The first material was based on a carbon fibre reinforced epoxy pre-preg. This was transformed into a composite using an autoclave (Fig. 1.1a). Pre-preg composite could be used in blade spars. For this material, the UD pre-preg layers are composed of HexPly ${ }^{\circledR}$ M21 matrix and UD HexTow ${ }^{\circledR}$ IMA carbon fibres. Full vacuum was applied on the stacked pre-preg, then 7 bar gauge for autoclave pressure at $180{ }^{\circ} \mathrm{C}$ for $120 \mathrm{~min}$. In this paper, this material will be referred to as Pre-preg material.

The second material is a carbon/epoxy manufactured by vacuum infusion. This material could be used to manufacture the blade body. For this material, the UD layers are composed of Tenax-E IMS65 carbon fibres and epoxy resin. The samples were made on a glass plate using a Teflon anti-adhesive layer, with a vacuum of 0.95 bars for the infusion process (Fig. 1.1b). After polymerization of the resin at room temperature $(24 \mathrm{~h})$, all the infused plates were cured at $65^{\circ} \mathrm{C}$ for $16 \mathrm{~h}$. In this paper, this material will be referred to as Infused material.

After obtaining the composite panels, different preparation steps were necessary before testing them. Specimen preparation is divided in seven steps (Fig. 1.1c), and the final one is the testing.

Additional information on materials and specimen preparation is available in [2].

\subsubsection{Intra-laminar Cracks Detection Methods}

An important parameter in material selection for tidal turbine blades is the resistance to damage initiation and propagation. In this section, intra-laminar tensile cracking is presented using tensile loading on different stacking sequences of 0 and $90^{\circ}$ layers. Samples of the Infused and Pre-preg materials with a $\left[0_{2}, 90_{2}\right]_{\mathrm{s}}$ stacking sequence were prepared and tested on an electro-mechanical testing machine at a loading rate of $1 \mathrm{~mm} / \mathrm{min}$. All specimen edges were polished before testing to improve observation, and to remove crack initiators after water jet cutting. This process allowed extracting Pre-preg specimens and Infused specimens with the specified geometries (i.e. Length $\times$ Width $\times$ Thickness: $250 \mathrm{~mm} \times 15 \mathrm{~mm}$ $\times 2.0 \mathrm{~mm}$ and $250 \mathrm{~mm} \times 25 \mathrm{~mm} \times 1.7 \mathrm{~mm}$, respectively).

Figure 1.2 provides a general overview of the mechanical test set-up. One edge of the specimens was painted white to improve observation of cracks. Then monitoring of the crack development was performed using two high definition (HD) cameras. The image acquisition frequency was $1 \mathrm{~Hz}$. In addition to this image monitoring method, the acoustic emission (EA) technique was used to both detect and locate the intra-laminar cracks. In this study, the monitoring of the crack kinetics, which corresponds to interfacial debonding and mesoscopic crack in $90^{\circ}$ plies, was performed using MISTRAS Micro II equipment. This latter allows recording AE activity within the material and, especially its evolution as a function of applied loading. Under mechanical loading, the micro-cracks generate transient elastic waves. The latter are referred to as $\mathrm{AE}$ waveforms. Four-channel $\mathrm{AE}$ equipment was used and two $\mathrm{AE}$ sensors (Fig. 1.2, right) were enough to both record and perform a linear localization of the AE sources (referred to as events). These two NANO 30 sensors were connected to two preamplifiers (IL40S model, gain set at $40 \mathrm{~dB}$ ). These preamplifiers were connected to the data acquisition card of the AE system. A silicone gel was used to ensure uniform contact and improve transmission of the waveform through the sensor area.

\subsection{Results Analysis and Discussion}

This section describes both the program that was developed to achieve automatic image processing and the statistical tools that were used to perform cluster analysis of $\mathrm{AE}$ events. Figure 1.3 provides a general overview of findings from the image processing method. Figures 1.4 or 1.5 provides a general overview of results from the cluster analysis of AE data. 


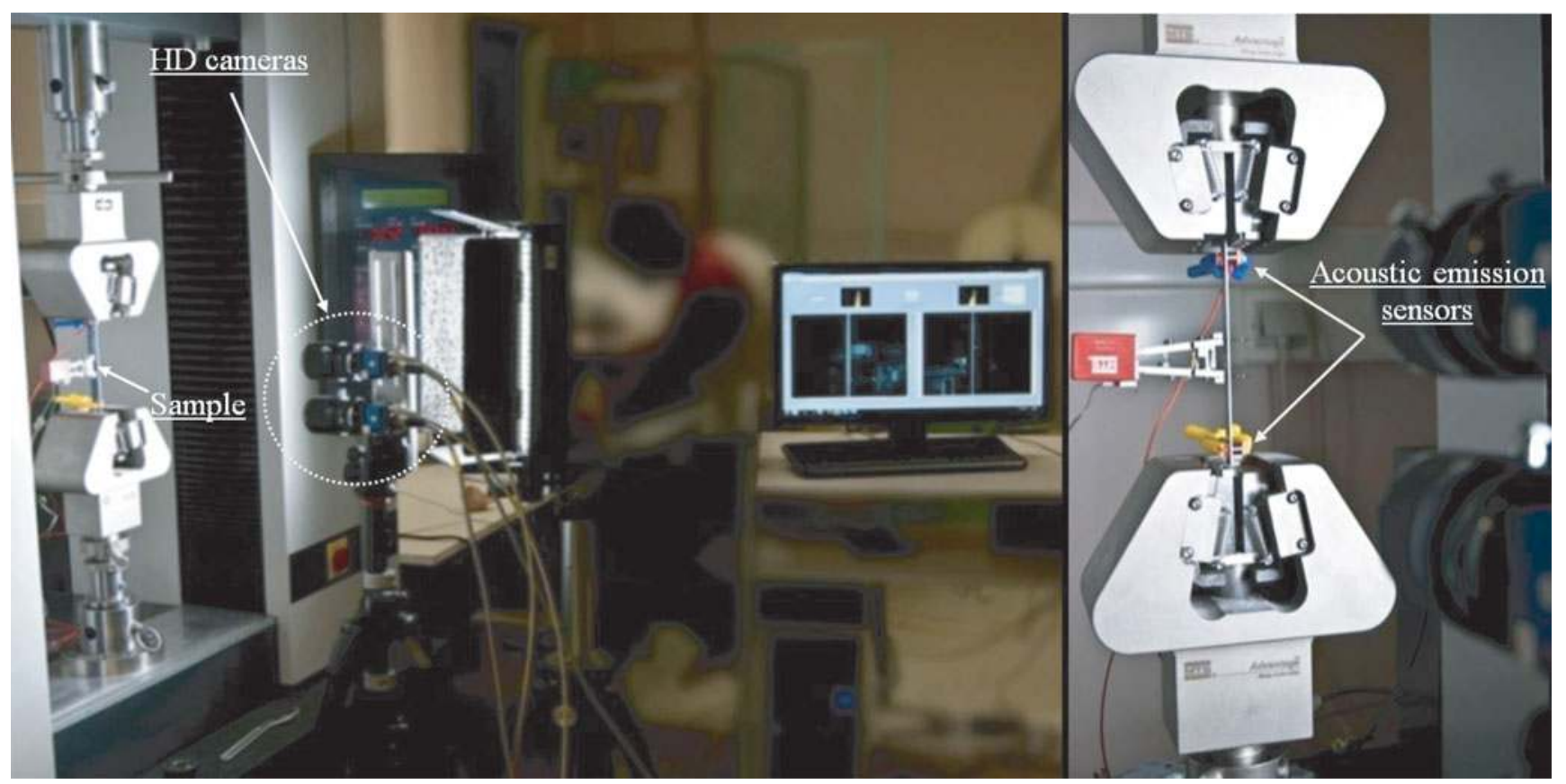

Fig. 1.2 Test set-up to measure intra-laminar tensile cracking by means of HD Cameras and Acoustic Emission technique

a

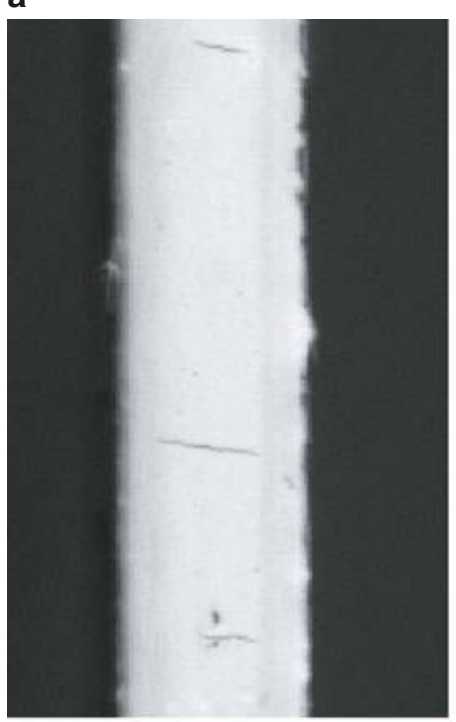

b

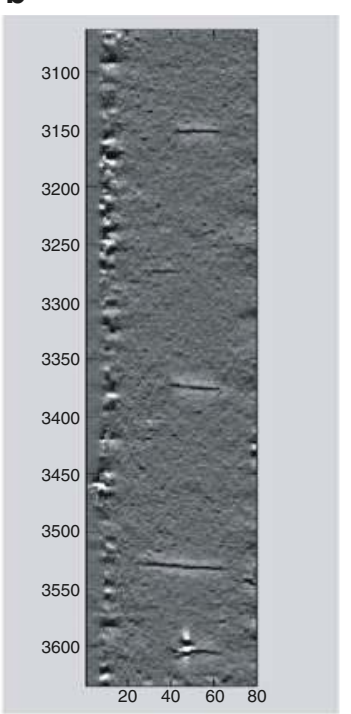

C

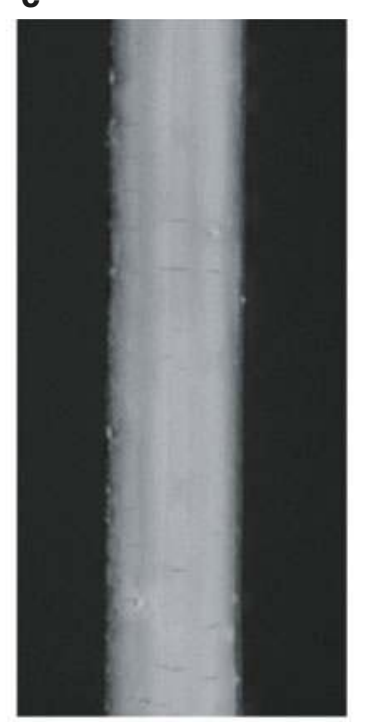

d

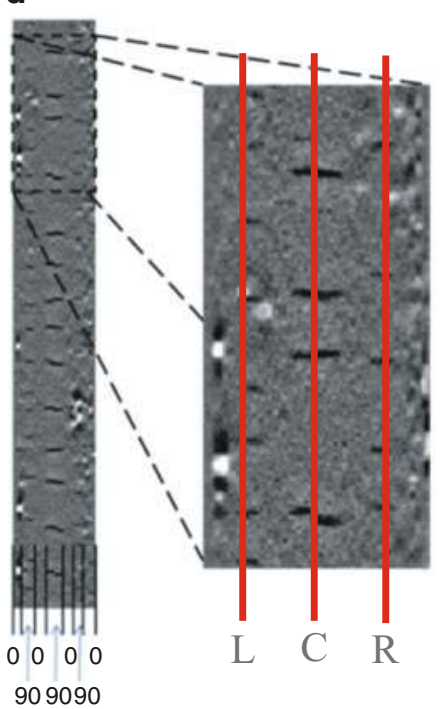

Fig. 1.3 Visualization of cracks before $(\mathbf{a}, \mathbf{c})$ and after $(\mathbf{b}, \mathbf{d})$ Matlab ${ }^{\mathrm{TM}}$ processing on a $\left[0_{2}, 90_{2}\right]_{\mathrm{s}}$ and $[0,90]_{4 \mathrm{~s}}$ sample respectively

\subsubsection{Image Processing}

To achieve automatic image processing and crack counting, a program was developed with Matlab ${ }^{\mathrm{TM}}$ software. The program processed the images to highlight the cracks, with a filter based on a Gaussian function convolution. Figure 1.3b shows an example of the image processing. The cracks were then counted automatically by differentiating levels of grey on a vertical line defined in the program (based on $90^{\circ}$ plies location). In the case of $[0,90]_{4 \mathrm{~s}}$ specimens, it is possible to count cracks along three different vertical lines (Fig. 1.3d). 

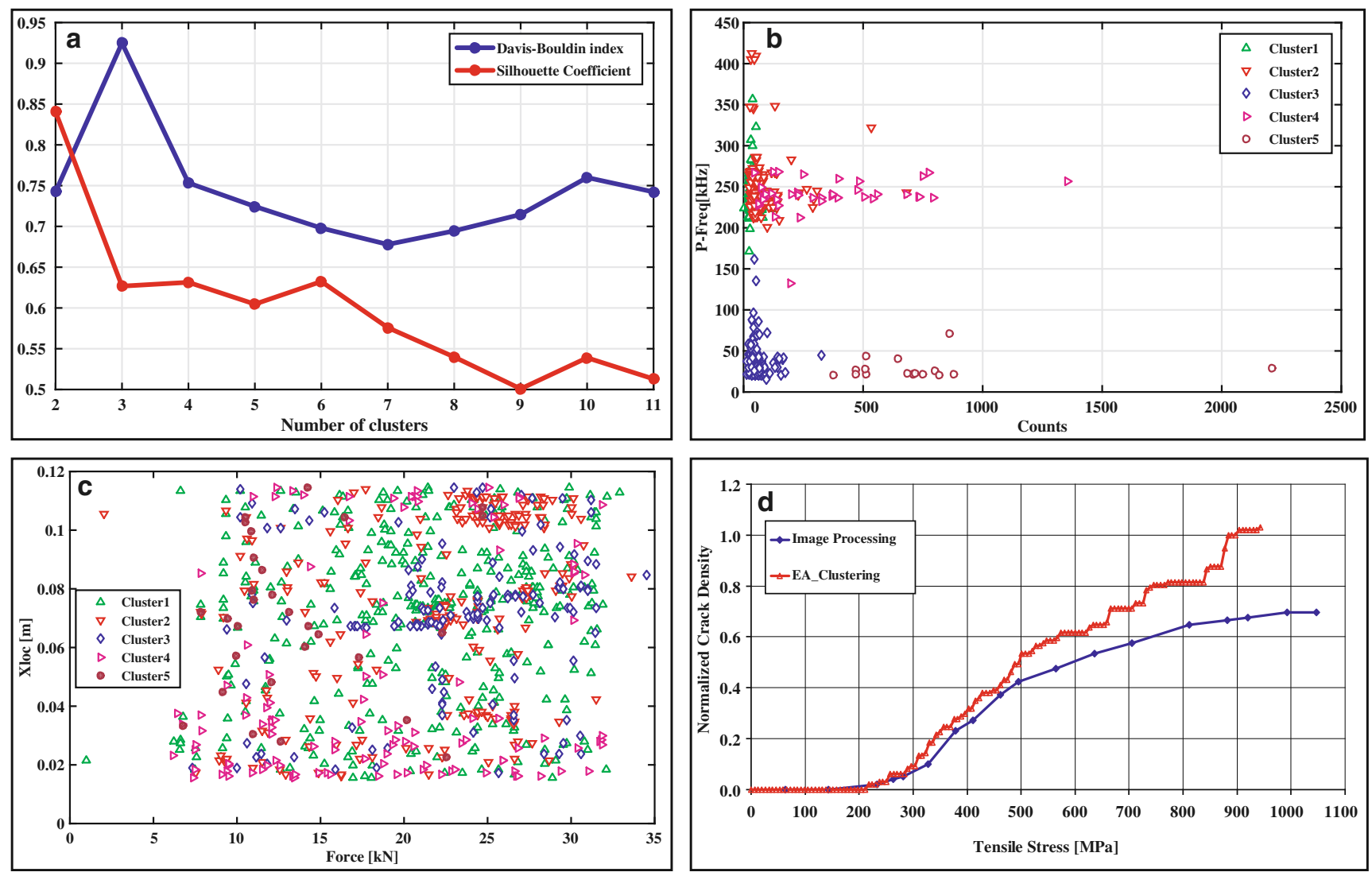

Fig. 1.4 (a) to identify the optimal number of clusters. Pre-preg $\left[0_{2}, 90_{2}\right]_{\mathrm{s}}$ : Cluster analysis of AE events to identify different failure mechanisms (b) - to locate Inter-ply cracks (c) - to monitor the evolution of normalized crack density as a function of applied stress (d)
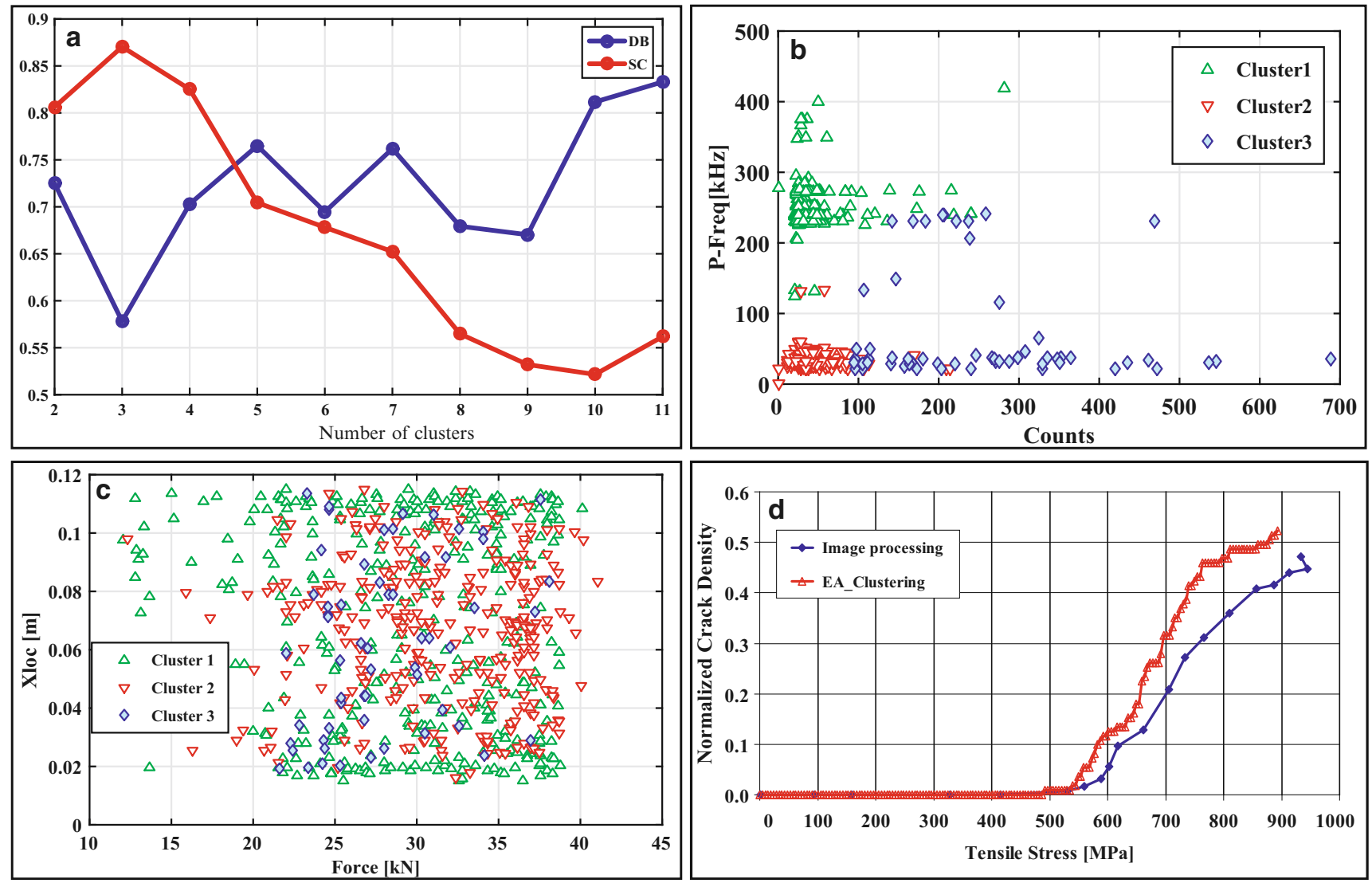

Fig. 1.5 (a) to identify the optimal number of clusters. Infused $\left[0_{2}, 90_{2}\right]_{\mathrm{s}}$ : Cluster analysis of AE events to identify different failure mechanisms (b) - to locate Inter-ply cracks (c) - to monitor the evolution of normalized crack density as a function of applied stress (d) 


\subsubsection{Cluster Analysis of AE Data}

$\mathrm{AE}$ events recorded during tensile tests on composite materials were subjected to cluster analysis, which resulted in identification of clusters of AE events. A Cumulative AE event of a selected cluster will be correlated with image processing results. This will allow identification of the failure mechanism which caused an AE event.

Cluster analysis is a statistical methodology to analyze AE sources. Before performing cluster analysis, the first and crucial step is to choose the $\mathrm{AE}$ features in order to eliminate irrelevant and redundant signals [5]. The selection of the relevant features was done using Laplacian score and correlation coefficients. Thus, from the nine AE features (time domain and frequency domain) selected using the AEwin software, four (amplitude, number of counts, peak frequency, and frequency centroid) were chosen as AE descriptors.

Among cluster algorithms, the most frequently used methods are K-means, self-organized map combination with $\mathrm{k}$-means and fuzzy-c means algorithm. K-means is the simplest and most effective method for AE signal clustering. To perform cluster analysis of the AE events recorded during the tests, Principal Component Analysis (PCA) and K-means++ algorithm were used to gather similar AE events into clusters. The cluster analysis was performed using the Statistics toolbox and functions in the SOM toolbox in Matlab ${ }^{\mathrm{TM}}$ software. The optimal number of clusters is chosen based on the values of both the Davis-Bouldin index (DB) and the Silhouette Coefficient (SC). The optimal number of clusters leads to a highest value of SC and a lowest value of DB. With these values, the clusters are dense and well separated, which corresponds to the standard concept of a cluster [6].

Figure 1.4 shows the results of cluster analysis on AE data from the Pre-preg specimen $\left[0_{2}, 90_{2}\right]_{\mathrm{s}}$. For both methods, image processing and cluster analysis, the intra-laminar cracks evolution is evaluated in terms of normalized crack density (Fig. 1.4d), which is the number of cracks multiplied by the thickness of the $90^{\circ}$ plies and divided by the observation length (around $100 \mathrm{~mm}$ ).

On Fig. 1.4, the cluster analysis presented shows that the optimal number of clusters is six (Fig. 1.4a). The clustering is however restricted to an analysis of five clusters. The sixth cluster could be AE events with peak-frequency greater than $300 \mathrm{kHz}$. Figure 1.4b presents the projection of the five clusters of AE events onto a two-dimensional plot by two principal components. The two AE features, peak-frequency (P-Freq) and number of counts (Counts) are the most important AE parameters in the chosen set of five, as evidenced by the good separation of the clusters points in the space of these two parameters (Fig. 1.4b). AE events of Cluster\#5 (peak-frequency lower than $100 \mathrm{kHz}$ and a number of counts greater than 200) were associated with intra-laminar crack damage. Cumulative AE events of Cluster\#5 during the tensile test were used to both assess and plot the evolution of normalized crack density. Figure 1.4d shows a good correlation between the normalized crack density evaluated with acoustic emission (red triangles) and the one evaluated with image processing (blue circles).

Figure 1.5 shows the results of cluster analysis on AE data from Infused specimens $\left[0_{2}, 90_{2}\right]_{s}$. For both methods, image processing and cluster analysis, the intra-laminar crack evolution is evaluated in terms of normalized crack density (Fig. 1.5d).

On Fig. 1.5, the cluster analysis presented shows that the optimal number of clusters is three (Fig. 1.5a). Figure 1.5b presents the projection of the three clusters of $\mathrm{AE}$ events to two-dimensional plot by two principal components. The two $\mathrm{AE}$ features, peak-frequency (P-Freq) and number of counts (Counts) are the most important AE parameters in the chosen set of three, as evidenced by the good separation of the clusters points in the space of these two parameters (Fig. 1.5b).

$\mathrm{AE}$ events of Cluster\#3 (restricted to events with peak-frequency lower than $100 \mathrm{kHz}$ and a number of counts greater than 200) were associated with intra-laminar crack damage. Cumulative AE events of Cluster\#3 during the tensile test were used to both assess and plot the evolution of normalized crack density. Figure $1.5 \mathrm{~d}$ shows good correlation between the normalized crack density evaluated with acoustic emission (red triangles) and the one evaluated with image processing (blue circles).

\subsubsection{Evolution of Crack Density}

The findings in terms of normalized crack density from both image processing method and AE cluster analysis are compared. Results for specimens from the same material are also compared (Fig. 1.6a, b or Fig. 1.6c, d).

On Fig. 1.6, every graph shows a good correlation between normalized crack density evaluated by using image processing and the one monitored by means of $\mathrm{AE}$ cluster analysis. For each specimen, $\mathrm{AE}$ events with a peak frequency lower than $100 \mathrm{kHz}$ and a number of counts greater than 200 are associated with intra-laminar crack damage. 

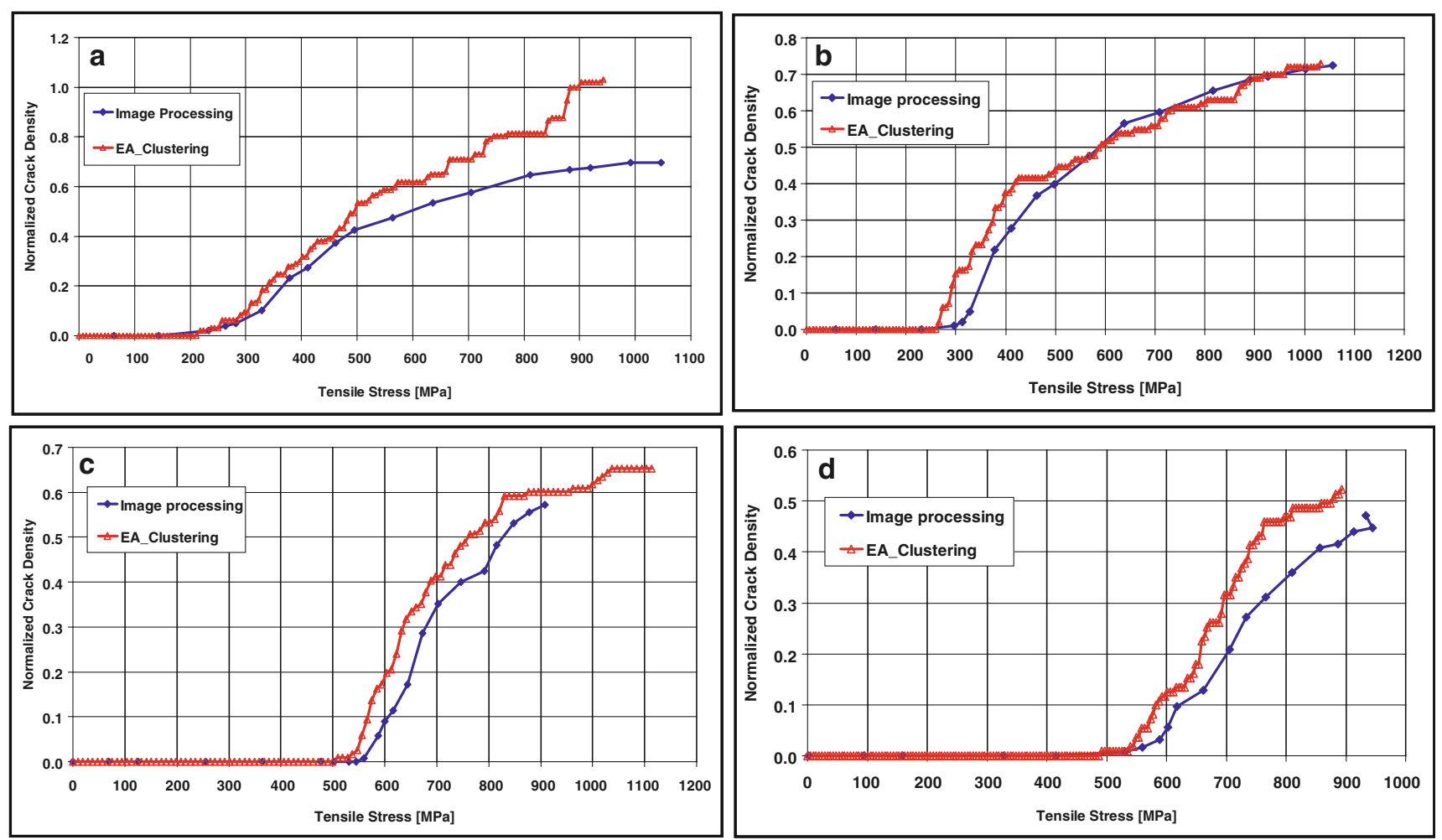

Fig. 1.6 (a, b): Pre-preg $\left[0_{2}, 90_{2}\right]_{\mathrm{s}}-(\mathbf{c}, \mathbf{d})$ : Infused $\left[0_{2}, 90_{2}\right]_{\mathrm{s}}$ : Cluster analysis of AE events vs. Image processing to monitor the evolution of normalized crack density as a function of applied stress

For each composite material, Pre-preg (Fig. 1.6a, b) and Infused (Fig. 1.6c, d), the evolutions of normalized crack density are similar. However, when comparing findings from the two materials, a first inspection of these figures reveals a significant effect of the thickness of the $90^{\circ}$ plies on the damage threshold. For the Pre-preg material, initiation of damage starts at around $250 \mathrm{MPa}$, whereas for the Infused material, the first cracks start appearing at around $500 \mathrm{MPa}$. In a previous study [7], it has been shown that strength in the transverse and shear directions depends on ply thickness. Thinner plies (Infused material) have higher strength than thicker ones (Pre-preg material).

\subsection{Conclusion}

Throughout their service life, tidal turbine blades will be subjected to many marine aggressions, in particular due to sea water penetration into their composite components. In this study, three carbon/epoxy composites, which are all candidates for tidal turbine blades, have been studied and compared. In this paper, the mechanical behavior of two of these composite materials (Pre-preg and Infused) before water ageing is investigated in terms of crack density within the material. Samples of the Infused and Pre-preg materials with a $\left[0_{2}, 90_{2}\right]_{\mathrm{s}}$ stacking sequence were prepared and tested on an electro-mechanical testing machine. Two methods, image processing and Acoustic Emission (AE), were used to both detect the intra-laminar cracks and monitor their evolution during the tensile test. For both methods, image processing and cluster analysis, the intra-laminar crack evolution has been evaluated in terms of normalized crack density.

To achieve automatic image processing and crack counting, a program was developed with Matlab ${ }^{\text {TM }}$ software. The program processed the images to highlight the cracks, with a filter based on a Gaussian function convolution. The cracks were then counted automatically by differentiating levels of grey on a vertical line defined in the program (based on $90^{\circ}$ plies location).

$\mathrm{AE}$ events recorded during the tensile tests on composite materials were subjected to cluster analysis, which resulted in identification of clusters of $\mathrm{AE}$ events. A Cumulative $\mathrm{AE}$ event of a selected cluster was correlated with image processing results. This allows the failure mechanism which caused an AE event to be identified. Two AE features-peak frequency and 
number of counts-represent adequately the AE events clustering. This unsupervised classification allows the AE events that were generated by intra-laminar cracks to be identified.

In this study, the findings are as follows. AE events that were generated by intra-laminar cracks exhibit a peak frequency lower than $100 \mathrm{kHz}$ and a number of counts greater than 200. This acoustic signature of the intra-laminar crack was validated by comparing the normalized crack density resulting from the AE technique with the one from image processing. A Good correlation between results from the two methods was obtained. For each composite material, Pre-preg and Infused, the evolutions of normalized crack density are similar. However, when comparing findings from the two materials, the results reveal a significant effect of the thickness of the $90^{\circ}$ plies on the damage threshold. For the Pre-preg material, initiation of damage starts at around $250 \mathrm{MPa}$, whereas for the Infused material, the first cracks start appearing at around $500 \mathrm{MPa}$. Thinner plies (Infused material) have higher strength than thicker ones (Pre-preg material).

Since the acoustic signature of the intra-laminar crack has been identified, the effect of sea water ageing on the mechanical behavior of the studied composite materials can now be investigated. Effects of water ageing on the acoustic signature will be also evaluated.

Acknowledgments This research project was partially supported by the Bretagne Region. We thank Thomas Bonnemains and Eric Lolive of the IUT in Brest for manufacture of the infused materials. We also thank Li Li (Donghua University, China) and Stephan Lomov (KU Leuven, Belgium) for the cluster analysis tool.

\section{References}

1. Chalmers, D.W.: The potential for the use of composite materials in marine structures. Mar. Struct. 7(2-5), 441-456 (1994)

2. Tual, N., Carrere, N., Davies, P., Bonnemains, T., Lolive, E.: Characterization of sea water ageing effects on mechanical properties of carbon/epoxy composites for tidal turbine blades. Compos. Appl. Sci. Manuf. 78, 380-389 (2015)

3. Boisseau, A., Davies, P., Thiebaud, F.: Sea water ageing of composites for ocean energy conversion systems: influence of glass fibre type on static behaviour. Appl. Compos. Mater. 19(3-4), 459-473 (2012)

4. Nairn, J.A., Hu, S.: The initiation and growth of delaminations induced by matrix microcracks in laminated composites. Int. J. Fract. 57(1), 1-24 (1992)

5. Li, L., Lomov, S., Yan, X., Carvelli, V.: Cluster analysis of acoustic emission signals for 2D and 3D woven glass/epoxy composites. Compos. Struct. 116, 286-299 (2014)

6. Li, L., Lomov, S., Yan, X.: Correlation of acoustic emission with optically observed damage in a glass/epoxy woven laminate under tensile loading. Compos. Struct. 123, 45-53 (2015)

7. Camanho, P.P., Dasilva, C.G., Pinho, S.T., Iannucci, L., Robinson, P.: Prediction of in situ strengths and matrix cracking in composites under transverse tension and in-plane shear. Compos. Appl. Sci. Manuf. 37(2), 165-176 (2006) 